\title{
To Examine the Influence of Gender Interaction on Academic Achievement of Learners
}

\author{
Mwangi Newton Irungu \\ Doctorate Thesis, \\ School of Education, University of Nairobi \\ Grace Nyagah \\ Professor, \\ School of Education, University of Nairobi \\ Dr. Mugambi Mercy \\ University of Nairobi, Kenya \\ School of Education, University of Nairobi
}

\begin{abstract}
This article aimed at examining the influence of gender interaction on academic achievement of learners. The study targeted public secondary schools in Murang'a County, Kenya and focused on Chemistry subject matter. Descriptive survey design was adopted for this study, while the study was guided by two null hypotheses: Ho1: There is no statistically significant effect of gender interaction on academic achievement of learners in Chemistry. Ho2: There is no statistically significant relationship between gender interactions and academic achievement of learners in Chemistry. The study was guided by social interaction principles advocated by Vygotsky Social development theory. A sample size of 32 public secondary schools, 384 form three students and 32 teachers of Chemistry were used for the study. Lesson Observational Checklist (LOC) was the main instrument for data collection while the Chemistry Achievement Test (CAT) provided scores for the dependent variable. Reliability and validation of the instruments were done through a pilot study in two public secondary schools that were not part of the sampled schools. The study was based on gas laws in Chemistry which is taught in form three class in term one while Quantitative and qualitative data was collected during that period. Results from the qualitative data revealed that, girls were more interactive than boys while the stereotype of classifying certain subjects as female or male ones is changing. Results from simple regression analysis indicated that, there is no statistically significant effect of gender interaction on academic achievement of learners in Chemistry. The statistic coefficient $\left(R^{2}=0.013\right)$ provided the amount of variation that can be accounted for by the independent variable which is gender interaction, implying the model explained $1.3 \%$ variation in academic achievement which is the dependent variable in this study. Therefore $98.7 \%$ change in academic achievement resulted from other factors that were not part of the model. Analysis from Pearson Product-Moment Correlation Coefficient $(r=0.1137)$ yielded a weak positive relationship implying that, there is no statistically significant relationship between gender interactions and academic achievement of learners in Chemistry. Therefore gender interaction does not contribute to learners' academic achievement.
\end{abstract}

Key words. Academic achievement, gender interaction, social interaction, cognitive development, socio-cultural differences. 


\section{INTRODUCTION}

The term gender refers to a wide range of biological, behavioural, physical and mental characteristics regarding to and differentiating the female and the male population (Adigun, Onihunwa, Irunokhai, Sada \& Adesina, 2015). Gender and sex are not interchangeable; the term sex refers to the biological distinction between the two genders and cannot change. Hence, gender is an aspect concerning the responsibilities, roles, opportunities, constraints, and needs of males and females in all aspects of social context (Filgona \& Sababa, 2017). Therefore, gender, is a critical issue, which has attracted the attention of teachers especially due to the fact that gender equality is a focus in all sectors of life. It is because of this that the current study attached a lot of importance in examining the extent to which learners' academic achievement is affected by gender whose primary basis is socio-cultural distinctions between males and females.

It can therefore be argued that, academic achievement in relation to gender interaction may be affected by socio-cultural differences between girls and boys. As noted by Palt, 2018), it is crucial that African countries prioritize gender diversity and appreciate the role that women can play in the development of scientific solutions to address these issues at local level. The author continue to reveal that today the proportion of men scientists in Africa remains high compared to women; the proportion of women in the research field is $29 \%$ for the whole of sub-Saharan Africa while it exceeds $45 \%$ in Tunisia and Egypt. In Kenya, out of a population of 48 million people, 300 people get a PhD every year, and only 75 of them are women. This shows how serious women are discriminated against especially in Africa. Therefore gender discrimination is a critical issue faced by our students in our schools and many studies have found teachers do not give equal attention to male and female learners. If learners are regularly exposed to these stereotypes it may send negative messages about how they are expected to behave according to their gender (Lindsey, 2013). Moreover, potential growth and development of learners is limited when they are faced with gender stereotypes.

Therefore, the gender of a student can be a fundamental variable in explaining academic performance of learners. One of the intriguing explanations on variation in gender on achievement of students academically relates with the dynamics of gender interaction between the student and the teacher, especially to gender combination of students and teachers. Recently, the findings of research related to gender interaction between students and teachers have affected many changes in educational policy globally (UNESCO, 2000).

Filgona1i and Sababa (2017) noted that, treatment of male and female students should be treated equally during teaching and learning and all students should be provided with equal opportunities and same encouragement level and engagement irrespective of gender. Therefore to provide equal chances to learning, teachers must avoid biasness in the way different gender are handled academically and in particular interaction with learning materials, teachers and classmates. Lauren (2012) noted that within the learning environment, gender plays a critical role, since teachers respond differently to boys and girls within the same classroom. Therefore teachers tend to confirm the traditional gender roles taught by the society. For instance boys are often praised for their knowledge while girls are praised for their obedience. One of the study's conclusions was that teachers should endeavour to reduce the gender stereotyping that students may hold from the home environment. Another study by Berk (2006) revealed that in a mixed class, teachers interacting more with boys than girls are likely to interrupt girls more often than boys during discussions. The current study will focus on the extent of gender stereotype during Chemistry lessons in the Kenyan context. 
Gender bias makes boys more active than girls in the classroom during the teaching and learning process (Christine, 2015). An investigation by Nana (2012) in Georgia revealed that, instructors mostly treat students of various genders differently and have stereotyped the potential of boys and girls. The research additionally revealed that regardless of better academic outcomes in girls', their potentials are underestimated leading to low morale and their conduct is confined to stereotyped female roles. This is likely to promote gender-biased perception resulting in unequal treatment and low self-esteem among girls. Would this lead to low academic achievement in girls? In this study a multi-scale attitude questionnaire was used as the main instrument and all subjects were involved. The current study used observational schedule as the main instrument and used Chemistry subject within the Kenyan context.

Oluwatosin and Ogbeba (2017) study on impact of gender on senior secondary Chemistry students' academic achievement in stoichiometry using hands-on activities revealed insignificant difference in average achievement score between males and female students who were taught stoichiometry with the use of hands-on activities. The study also found that there was a significant relationship between the techniques and gender of average achievement score of learners in stoichiometry. To enhance learners' academic achievement in stoichiometry, the study recommended that, because the activity of hands-on is not sensitive to gender, students of both genders should be involved in the activities. The study adopted a quasi-experimental research design. The current study adopted a descriptive research design while the main instrument was an observational schedule that investigated the effect of gender interaction on learners' academic achievement.

In their study Nematullah, Mohammad and Saeed (2008) noted that interaction patterns are to some extent gender-related. One of their recommendation was that self-esteem and the social values found in both genders can be investigated to establish why males speaks more even in female-dominated classes than females. However, in-depth interviews can reveal more and complement the findings of this study. The current study used observational schedules which were complimented by interview schedules and learners' questionnaire. Durán (2015) did a case study whose purpose was to investigate the perception of teacher and learner on gender in an EFL class and its manifestation in their discourse patterns. Results showed difference in the manner boys and girls interacted during teaching and learning. The study also found that girls had low self-esteem as a result of the opinion that lacked respect and value that they received on their responses from their male peers. The study revealed that, part of teachers' and learners' conceptions on gender was stereotypes and were maintained greatly. In regard to gender, the attitude of teachers tends to be in the favor of the boys. The female learners seemed aware of the conscious or unconscious indifference of the teachers towards them, which in turn affected their interactions, self-esteem and confidence in the learning of English. This may affect the quality of learning leading to low academic achievement.

A study by Onyegegbu (2004) noted that boys were more active in interactions than girls. However, findings from a study by 0'Connor, Dearing and Collins (2011) had different results that revealed that girls are more likely to interact among themselves than boys by working well in small group settings and discuss a problem or task ideas while boys prefer to work alone, and will often "argue over who will lead when working in a group". Therefore girls have the same ability to boys if given equal opportunities. From this study it was argued that, teachers all over the world being the agents of change, have a challenge to change the gender perception.

Fatokun and Omenesa (2015) carried out a study to determine the effect of prior knowledge and classroom interaction on learners' academic achievement in Chemistry. Quasi 
experimental design was adopted while two schools were purposively sampled. The study revealed a positive significant effect of treatment on achievement of learners' in Chemistry. However, insignificant effect was found on learners' academic achievement in Chemistry regarding gender. The study further revealed insignificant mean variation in prior knowledge between the two groups, control and experimental groups. One of the recommendations of the study was that teachers should be sensitive to gender and make sure that teaching of Chemistry is done in an interactive classroom style to improve quality learning that is likely to yield high academic achievement in Chemistry. The current study explored more on gender interaction and classroom interactions and used 32 schools with a view of getting authentic results. A descriptive survey design was also adopted for the current study.

Additionally, the results from a study by Fatokun and Omenesa (2015) revealed insignificant variation in both genders difference and academic achievement despite the fact that girls were not as active as boys in the classroom interaction during teaching and learning. Implying, students can achieve high academic scores irrespective of their gender. Teachers should therefore create an environment which encourages students of both genders to have equal and active interactions during learning and teaching process. This study focused on the same but in the Kenyan context to authenticate these findings.

According to Nana (2012), there are few researches comparing classroom interaction of male and female students and the few studies that have been conducted show that there is a clear cut line in differences that relate to gender. Wenhua (2012) for instance in a study entitled Gendered EFL Classroom Interaction; case of China senior middle school further noted that researches that reflect the classroom cooperation of girls and boys are generally rare, yet a couple of the researches report obvious gender biasness. The study was done in China and involved English subject. The current study was in Chemistry and in the Kenyan context.

Results of a study by Nnamani and Oyibe (2016) on gender and academic achievement of secondary school Students in social studies in Abakaliki urban of Ebonyi state revealed that the mean academic achievement score of boys' learners in post primary school was lower than the mean academic achievement scores of girls' learners. Further findings from the same study indicated that: boy and girl post primary school students taught social Studies by men teachers had higher mean scores than boys and girls learners taught Social studies by women teachers and girl learners taught Social studies by men teacher performed better than masculine learners taught social Studies by men teachers and vice versa. The study further revealed that there are significant difference in the mean academic achievement of post primary school learners in Social Studies based on gender. The study was on effect of gender on students' mean academic achievement, and effect of teachers' gender on the mean academic achievement of boy and girl learners while the current study focused on effect of gender interactions and learners' academic achievement in Chemistry. However, Burusic, Babarovic and Seric (2011) did a study whose objective was to examine the teacher-pupil gender interaction effect on pupils' school academic achievement in Croatian elementary schools. The study used standardized knowledge tests and school marks for almost all subjects in the school curriculum to measure the pupils' school achievement. The study revealed that results of the standardized tests were the same irrespective of gender and therefore learners achieved the same academically irrespective of gender. However, on effects of teachers' gender on learners' achievement, which was measured using Students' knowledge, it was established that the female teachers were more superior in standardized achievement tests only. Therefore it can be argued from this study that, there is insignificant relationship between the gender of the student and the effect of educators' interactions. This study further revealed that girls tend to perform better than boys during elementary and early post primary education, even in 
subjects like Mathematics and sciences which are always considered to be "masculine subjects." From the results of this study, it can be argued that, if teachers avoid gender biasness, then both genders have the same intellectual capacity to perform the same. The current study intends to authenticate the results of this study using observation as the main tool of instrument of data collection using secondary school students from a different cultural background.

Almut (2017) in a study on gender differences in students' motivation in physical science: are teachers' implicit cognitions another piece of the puzzle? The researcher observed that learners are motivated better by teachers who are of the same gender because they could act as their role models. In addition the study noted that educators prefer presenting tasks in contexts that favors same-sex students which are associated with their own gender. Further, Almut (2017) revealed that the stereotype of educators that science-is-male has a positive relationship with self-concept of male but has a negative relationship with the motivational belief of females. The results of the study agreed that teachers' stereotypes contribute varying motivational beliefs between the genders which could also be as a result of gendered educational choices. Girls are likely to select humanity based courses while boys are likely to select science oriented courses. Such beliefs may have an effect on gender in academic performance of learners in different subjects.

Findings of a study by Akabogu and Ajiwoju (2015) on effect of gender and school location on secondary school learners' achievement in English vocabulary in junior secondary schools in Akoka South Education Zone Ondo State revealed that gender positively and significantly affects the achievements of secondary school learners in English vocabulary. Therefore, the average score of females was lower compared to that of male students in English vocabulary achievement test. One of the recommendation of the study was that teachers, school administrators and stakeholders need to change and provide equal learning opportunities to boy and girl learners. Ajai and Imoko (2015) carried out a study to assess gender differences in Mathematics achievement and retention by using Problem-Based Learning (PBL). The findings of the study showed insignificant variation between students of both genders when taught algebra with the use of PBL establishing that students of both genders have the ability to compete and collaborate in Mathematics. It can therefore be argued from the findings of this study that academic achievement of learners is a function of orientation and not gender.

However, the finding of a study by Nnamani and Oyibe (2016) revealed that both learners and teachers' gender have effects on learners academic achievement in social studies in Abakaliki Urban of Ebonyi state. It was the opinion of the researchers that if teachers and other stakeholders in education pay attention to gender issues, the problem of differences that occurs in learners' achievement in school will be appropriately addressed. The three studies did not address the impact of gender interaction on academic achievement of learners' which was the focus of this study.

In a study carried out by Makila (2015) in Sweden, girls and boys were observed when doing a science practical in single and mixed-sex classes. The study purposed to create awareness of the male dominance in physical sciences among teachers and to help them develop strategies to arrange their teaching in a way that was more suitable for both sexes. The findings showed that in the control group, girls in mixed-sex groups spent their time mostly watching and listening instead of actively taking part in the assignment. In the experimental groups, the hands-on task-time was more equally distributed, but even in this group the girls spent more time listening and watching than the boys did. It can be concluded that, boys were more active than girls but the study did not address the effect on learners' academic achievement. Another 
result of the study was that the children worked in a more cooperative manner when they were allowed to choose whom to work with, but the study did not indicate the preferred gender for interaction by the learners.

One pattern that the researchers also noted was that in the teacher formed mixed-sex small groups, the boys were often the first ones to take up the science equipment required to finish the assignment without sharing them with the girls. All the groups received only one set of equipment, so the girls started to work with them after the boys had finished, but in most cases they did not have the time to finish their work during class time. The results of this study shows that girls still perceive themselves as inferior to boys during science lessons. Teachers have continued encouraging girls but the girl child still wants to retain the traditional back seat when working in the same environment with the boy child. More studies need to be carried out to find out the reasons why the girl child remain inactive in the presence of boy child. The current study explored more on gender interaction and academic achievement from the Chemistry point of view and in the Kenyan context.

Other studies have found boys to be more interactive than girls. For instance Marcus and Joakim (2016) who researched on gender variation in boys' and girls' perception of teaching and learning Mathematics found that boys use group work discussion more compared to girls and are more active during the lesson than girls. Boys received more attention because it is believed that they are very disruptive, and therefore, receiving more attention was a precautionary measure to avoid them going off the task.

Because of that belief, girls received less attention and their involvement in class was low as compared to boys, which could explain why girls' academic performance in Mathematics was generally lower compared to boys'. One of the recommendations of the study to fill this gap was that teachers need to help girls interact more in classroom during teaching and learning process. While the study was on Mathematics, Chemistry was the focus of the current study. The results from a study by Firooz (2016) showed an independent t-test revealed insignificant variation between both genders' talk and teaching style. The current study intended to find out if gender difference has an impact in the academic performance in Chemistry in the Kenyan context.

A study by Sheeba and Imran (2015) whose aim was to evaluate the effect of stress and selfesteem and gender's effect on learner academic achievement in selected private universities of Pakistan, revealed that self-esteem and stress were strongly correlated but gender and GPA of the learners were insignificantly correlated. The study further revealed that, analysis of selfesteem effects and impact of stress on GPA established that both effects insignificantly correlated with academic achievement of students. The study therefore concluded that stress level and self-esteem do not significantly influence academic achievement of students in private institutions of higher learning which is in agreement with already existing literature. This study focused on stress and self-esteem as the independent variables, and the current study focused on gender interaction as the predictor variable. While this study was on university students, secondary school students were the focus of the current study.

A study by Noureen, Chaudhry and Manzoor (2012) used observational schedule only to collect data through modified Flanders Interaction Analysis Category system (FIACS) instruments while data was analyzed using ANOVA, t-test, frequency tables, mean, standard deviation and Pearson correlation coefficient. The results of the study showed no statistically significant impact between the mean oral behavior scores of men and women instructors. To authenticate the results of this study, the current study used the same instruments in a target population 
with different cultural beliefs. The researcher in addition analyzed data further by using chisquare, regression analysis and thematic analysis.

A study by Hoque, Razak, Mosa \& Reazul (2013) attempted to find out the impact of teachergender interaction on primary pupils' academic achievement in Malaysia. Classes taught by women had higher test scores than classes taught by men. Therefore the general findings of the study were that females are better in teaching primary schools compared to men; this is because naturally women spend a lot of time with children than men giving those skills to interact. This gives female teachers an advantage of being better teachers in terms of social interaction in class making learning interesting and meaningful. Several studies have shown similar results.

For instance a study by Dee (2013) carried out in the United States purposed to investigate whether the achievement of a learner is influenced by a teacher of the same gender. It was established that assigning a student teacher of same gender has a significant positive effect on learners' academic achievement of students of both genders. For instance, the perception of girls on usability of science in the future is increased with the assignment of a female science teacher and vice versa. Another study carried out by UNESCO found that learners instructed by female teachers are likely to achieve better scores than learners instructed by male teachers (UNESCO 2000, 2005). Female teachers are patient, gentle, compassionate, and friendlier. This could explain the findings of a study by Myhill \& Jones (2006) which revealed that, worldwide statistics have shown that majority of teachers are female. Probably women teachers are motherly, provide warm interaction environment that enhances desire to learn among the learners, hence raising the academic achievement.

A similar study done in Tunisia by Natasha (2016), indicated that female teachers improve the academic performance of learners depending on the economic level of the location of the school; in low economic areas girls significantly benefit from female teacher more than boys. However, in high economic areas female teachers are beneficial to all learners regardless of gender. Therefore the results of this study indicate that gender interaction has an effect on learner's academic achievement. Is it that female teachers are better in terms interaction than males? The current study will attempt to authenticate these findings from gender interaction point of view and in the Kenyan context.

Torberg and Linn (2011) explored the educational evaluation schemes and gender gaps in student achievement in Norway and the study revealed that, in Norwegian, girls perform better academically when assessed by a male teacher, and in Mathematics girls perform better academically when assessed by low-experienced teachers. One interpretation of the results was that teachers favour girls, either intentionally or not. The study concluded that, the gender grading gap seems to be related to characteristics of the teachers. The current study investigated interaction of teachers of Chemistry with both boys and girls with a view of exploring interaction gender disparity among male and female teachers with boys and girls learners and effect on academic achievement. Perkins, Kleiner, Roey and Brown, (2004) noted that, female students attain higher academic achievement in all subjects, including Mathematics and natural sciences in all the levels while a study by Gallagher and Kaufman (2005) revealed that several test of knowledge administered internationally shows that boys perform better on standardized Mathematics tests while girls achieve better educational results in reading and language tests. The two studies were silent on effect of gender interaction that was addressed by this study. Findings of a study by Adigun, Onihunwa, Irunokhai, Sada and Adesina (2015), revealed no significant variation between gender and academic performance in computer studies. The results of this study can be interpreted to 
mean that, there are no distinguishing cognitive, affective and psychomotor skill achievements of learners in respect of gender. Though without significant difference in the administered test girls had slightly higher achievements scores compared to boys in public schools. From the reviewed literature it appears like the girl child is no longer threatened in terms of gender discrimination and further studies are necessary to establish the true position of effects of gender on learning globally.

Moreover, numerous studies indicate the existence of differences in achievement based on gender and age with no focus on learners' interaction. For instance findings from a study by Toni, Julija and Gordana (2018) indicate that female students achieve higher academic achievement from young age (kindergarten) to university level. It was also established that, girls achieved higher scores in all subjects, including Mathematics and natural sciences (Mickelson, 1989; Perkins, Kleiner, Roey and Brown, 2004 as (cited in Toni, Julija and Gordana 2018). At the same time, several test of knowledge administered internationally indicate that boys perform better on standardized Mathematics tests while girls achieve better educational results in reading and language tests (Baker and Jones, 1993; Beller and Gafni, 1996; Gallagher and Kaufman, 2005 as (cited in Toni, Julija and Gordana, 2018).

Gender issues are therefore critical and require more research because it is increasingly becoming clear that the boy child is threatened in learning institutions all over the world. For instance Camille (2016) observed that, boys are increasingly performing poorly than girls at school and this has increased the boy's risk to drop out of school, few college/university attendance, and/or un-employability. Camille (2016) further noted that in the Organization for Economic Co-operation and Development (OECD) countries, 66\% of females entered institutions of higher learning in the year 2009 while $52 \%$ were male and the gap is continuously increasing.

For the European case, in the year 2015, $43 \%$ of females aged 30-34 completed their tertiary education while only $34 \%$ of males of the same age completed. The gap had increased by $4.4 \%$ over the past decade and therefore there is need to identify the reason behind the ever widening gap. From the reviewed literature many studies have been done on academic achievements and gender, but little focus have been done on gender interaction and academic achievement. Therefore, the current study investigated if gender interaction has any effect on academic achievement while the identified gender disparity were addressed. This study was based on Chemistry subject and in the Kenyan context with a view of authenticating the results of earlier studies and filling the identified gaps.

\section{Objectives of the study}

i. $\quad$ To examine the students perceptions on gender interaction in class.

ii. To establish the gender interactions between teachers and students in class.

\section{Research hypotheses}

Ho1 There is no statistically significant effect of gender interaction on academic achievement of learners.

Ho2 There is no statistically significant relationship between gender interactions and academic achievement of learners.

\section{METHODOLOGY}

The study used descriptive survey design while both quantitative and qualitative methodologies were used. The mixed methods approach is suitable when diverse information is required from many stakeholders (Greene, Benjamin \& Goodyear, 2001). Qualitative data is 
mainly in the form of words rather than numbers and is collected mainly through observation and interviews or content analysis (Mugenda \& Mugenda, 2003), while (Kothari, 2012) states that qualitative research uses measures and techniques with no discreet numerical data. The target population for this study was 120 public secondary schools in Murang'a County that had scored an average mean grade of D+ to C- between the year 2010 and 2017, and a sample of 32 secondary schools that were used for the study. Therefore the 120 public secondary schools were purposively selected while the 32 sampled schools were selected using simple and stratified sampling so as to take care of gender.

The main tools for data collection were Lesson Observational Checklist (LOC) and Chemistry Achievement Test (CAT). However, Student Discussion Guide SDG), Document Analysis Guide (DAG) and Students' Questionnaire (SQ) were used to supplement the data with a view of getting credible results. Three pilot schools were selected for the purpose of measuring the validity and reliability of the instruments. The reliability of the instruments was measured using Pearson Product-Moment Correlation Coefficient. Any instrument with a reliability coefficient less than 0.70 was reviewed. Validation of the instruments was done during the administration of instrument during the pilot study. The researcher sat at the back of the classroom in each of the sampled schools for 80 minutes and using the LOC recorded the behaviour of teachers and learners under investigation. CAT and SQ were then administered to the learners who were guided on how to fill the $S Q$ instrument. The researcher, gathered more qualitative data with the leaners using the SDQ and DAG. After data collection, the researcher checked the instruments for completeness and accuracy of information obtained. Data was coded appropriately based on the objectives of the study, arranged and grouped by use of SPSS Version 20 into sub-samples for common features and reactions coded to give basic statistical analysis. Descriptive data was analyzed and results presented in frequency tables and percentages while inferential statistics were analyzed using Simple Regression Analysis, one way ANOVA techniques, Pearson Product-Moment Correlation Coefficient and Chi square.

\section{RESULTS AND DISCUSSION \\ Students Perceptions on the Gender Interaction in class}

The first objective in this study stated that, "To examine the Students Perceptions on Gender Interaction in class". To achieve the objective, the students were asked to state and describe their level of agreement on statements related to gender interaction and their learning. In table 1 below, letters $\mathrm{a}, \mathrm{b}, \mathrm{c}$ and $\mathrm{d}$ represent statements that were rated by the respondents:

a- I prefer boy/boy (Boys only), girl/girl (Girls only) interaction during learning.

b-I am shy to interact in a class where boys are present.

c-I am shy to interact in a class where girls are present.

d-I prefer/would prefer interacting with male teachers during the teaching of Chemistry. e-I prefer/would prefer interacting with female teachers during the teaching of Chemistry. 
Table 1: Students Perceptions on the Gender Interaction in class

\begin{tabular}{|c|c|c|c|c|c|c|c|c|c|}
\hline $\begin{array}{l}\text { Students rating in } \\
\text { terms of the } \\
\text { following } \\
\text { statements }\end{array}$ & & SD\% & $\mathrm{D} \%$ & NS\% & $\mathrm{A} \%$ & SA\% & Mean & $\begin{array}{l}\text { Std. } \\
\text { dev }\end{array}$ & $\mathrm{Chi}^{2}$ \\
\hline \multirow[t]{3}{*}{$\mathrm{A}$} & Male & 26.8 & 5.4 & 6.5 & 36.0 & 25.3 & 3.25 & 1.547 & 0.802 \\
\hline & Female & 26.4 & 6.9 & 7.5 & 36.8 & 22.4 & & & \\
\hline & Male & 16.7 & 52.2 & 5.3 & 8.6 & 17.2 & 3.17 & 1.493 & $23.452^{* * *}$ \\
\hline \multirow[t]{2}{*}{ B } & Female & 38.5 & 2.9 & 4.0 & 39.7 & 14.9 & & & \\
\hline & Male & 35.5 & 4.3 & 4.8 & 34.4 & 21.0 & 3.24 & 1.517 & $17.605^{* * *}$ \\
\hline $\mathrm{C}$ & Female & 20.1 & 48.9 & 8.0 & 5.8 & 17.2 & & & \\
\hline \multirow[t]{2}{*}{$\mathrm{D}$} & Male & 11.3 & 3.8 & 7.0 & 55.9 & 22.0 & 3.60 & 1.317 & $16.395^{* * *}$ \\
\hline & Female & 18.4 & 8.1 & 10.9 & 35.6 & 27.0 & & & \\
\hline \multirow[t]{2}{*}{$\mathrm{E}$} & Male & 21.0 & 15.1 & 9.7 & 35.5 & 18.7 & 3.33 & 1.410 & $16.982^{* * *}$ \\
\hline & Female & 17.8 & 5.2 & 5.2 & 51.7 & 20.1 & & & \\
\hline
\end{tabular}

$\mathrm{SA}=$ Strongly Agree, $\mathrm{A}=$ Agree, $\mathrm{NS}=$ Not Sure, $\mathrm{D}=$ Disagree, $\mathrm{SD}=$ Strongly Disagree

*** represents significance level at $1 \%$.

The findings indicated in Table 1 shows that there is statistically significant variation in the opinion of the two groups in relation to the statements except on the statement 'I prefer boy/boy, girl/girl interaction during learning'. However, regarding the respondents' perception, $61.3 \%$ of boys agreed that, they prefer boy/boy interaction while $59.2 \%$ of girls preferred girl/girl interaction. The findings from the learners' perception indicate that learning would be more effective in one gender class. This is probably because each gender fear to display their academic weaknesses before the other which might affect the social interaction outside the class.

The Chi-square p-value was statistically significant at $5 \%$ confidence level for the following statements; I am shy to interact in a class where boys are present, I am shy to interact in a class where girls are present, I prefer/would prefer interacting with male teachers during the teaching of Chemistry and I prefer/would prefer interacting with lady teachers during the teaching of Chemistry. $X^{2}$ can only be used on data that is discrete. Chi-squared test is the independence test, the idea that one variable is not affected by another variable or is related with another variable. The test does not provide the level of the association but rather it estimates the likelihood that other factors aside from chance contribute to particular relationship (Best \& Kahn, 2011). In relation to the statement, 'I am shy to interact in a class where boys are present majority of male students (68.9\%) disagreed, compared to $54.6 \%$ of female students who agreed with the statement. While in relation to the statement, 'I am shy to interact in a class where girls are present', majority of female students (69\%) disagreed, compared to $55.4 \%$ of male student who agreed. These findings indicate the key contribution the gender of students play in their learning process. This is because both male (55.4\%) and female students (54.6\%) were not comfortable to relate with their male and female counterparts respectively. Therefore from the findings of this study, learning in a mixed class is not effective. Similar results are exhibited by a study conducted by Okeke (2007) in Nigerian which revealed that female students suffer discrimination from teachers overtly and covertly, knowingly and unknowingly which automatically put the girls in a disadvantaged position for achievement in classroom interaction especially in science related subjects.

The results of this study indicate that in mixed secondary schools gender may have a negative effect on learners' academic achievement. In relation to the student-teacher interaction based on gender, $77.9 \%$ of male students prefer interacting with male teachers during the teaching of 
Chemistry compared to $62.6 \%$ of female students. While in relation to classroom interaction with female teachers, $71.8 \%$ of female students agreed to the statement, compared to $54.2 \%$ of male students. The results imply that the preference of learners is for them to be taught by teachers of the same gender as theirs. This is because male learners prefer being taught by male teachers while female learners prefer being taught by female teachers. This might be because of the fact that teachers of the same gender as students understands the challenges the students go through and they can relate with each other well compared to another gender. Another reason could be cultural issues where for instance boys feel that females are inferior to males and therefore boys may look down upon a female teacher as not suitable to teach him. Such an attitude will lower the academic achievement of the learner.

These results are in conformity with results of a study done in England and USA by Ammermüller and Dolton (2006) on the gender interaction between teachers and students and its effects on the scholastic results. The results of the study revealed that, effects of possible gender interaction has received a lot of attention that performance of girls is better when they are taught by teachers of the same gender and that boys also perform better when they are taught by male teachers. The results further indicated that gender interaction between teachers and students have positive effects in teaching of Mathematics in England and not in USA. This implies that in England, with all the other factors held constant, teaching of Mathematics would be effective if boys are taught by male teachers and girls taught by female teachers. It was also noted that in both countries female teachers constitute of $75 \%$ of the entire population of teachers. It was therefore suggested that more men should be recruited in the teaching professional to narrow the disparity of male: female ratio as well as avoid disadvantaging the boy child. Therefore, gender is a critical issue during teaching and learning and because learners might find themselves in classes involving both gender and again cannot be taught by their preferred gender, then teachers must change the current perception of learners towards gender.

\section{Gender Interactions between the Teacher and the Students in Class}

The second objective in this study stated, "To establish the gender interactions between teachers and students in class" To achieve this objective, the researcher sat at the back of the classroom and recorded through tallying the frequency at which each gender of the student was involved in each interaction. The interaction activities included raising of hands, answering questions, asking questions, doing demonstrations, reading and doing other activities. The interactions behaviour were tallied using the observation checklist and the results presented in percentages in table 2 .

Table 2: Gender Interactions between teachers and students

\begin{tabular}{llcc}
\hline \hline Interactions & Gender & Frequency & Percentage (\%) \\
\hline Raises hands & Male & 17 & 44.7 \\
Answers questions & Female & 21 & 55.3 \\
& Male & 22 & 50.0 \\
Ask a question & Female & 22 & 50.0 \\
\multirow{5}{*}{ Demonstrates } & Male & 11 & 50.0 \\
& Female & 11 & 50.0 \\
Reads & Male & 6 & 31.6 \\
\multirow{2}{*}{ Does other activities } & Female & 13 & 68.4 \\
& Male & 6 & 46.2 \\
& Female & 7 & 53.8 \\
& Male & 5 & 41.7 \\
\hline
\end{tabular}


The results in Table 2 shows the percentages at which each gender portrayed in each activity. In relation to the students who raised their hands while in class, 55.3\% were female, while $44.7 \%$ were male. Girls were slightly more active than boys. The results further indicate that there was an equal number (50\%) of students who answered questions and asked questions in the class respectively. However, in relation to undertaking demonstrations in class, majority $(68.4 \%)$ of females were involved compared to $31.6 \%$ of the male. From the results of this study girls appeared more active undertaking the demonstrations in class than boys. The students were also involved in reading in class and majority of females students (53.8\%) were involved in reading compared to $46.2 \%$ of male students. Although a small difference, girls appears more active in reading than boys.

Finally, apart from engagement in classwork, 58.3\% of the females were involved in other activities such as helping the teacher rub the board and helping the teacher carry the chair after class compared to $41.7 \%$ of the male students. Again girls appeared more active in class. Therefore, the results arising from this study shows that, girls were to some extent more interactive than boys during teaching and learning. The findings are in agreement with several studies like 0'Connor, Dearing, \& Collins (2011) study which revealed that, the preference of boys is working alone and whenever they are working in groups they will argue on who should lead as opposed to girls who have a higher likelihood of cooperating and working effectively in groups, discussing issues and ideas pertaining a particular task. Vinson (2013) found that, the variation in treatment of students by teachers based on gender was significant in that male teachers are normally in favour of girls while female teachers favour boys. Hyacinth (2000) noted that the nature of teacher-student interaction shows some bias in favour of girls and although teacher-student interaction for boys did not correlate with academic performance, the interactions observed raised gender equity and moral issues that have implications for the teacher's role.

The findings of the current study could explain the results of a study by Milun, Mardesic and Kovac, (2011), which investigated if gender and age have an impact on student success. The findings further revealed that, female students performed better in eight courses: Introductory economics, Business mathematics, Accounting, Commerce law, Managerial accounting, Bank accounting, Accounting information systems, and Business marketing. In addition male students did not significantly outperform their female colleagues in any of the 34 classes. Additionally, a study by Chua and Mageswary (2015), established that the attitude of female students regarding Chemistry lessons were more positive than that of male students across the grade levels. Female students could be performing better because they interact more than male students. However, teachers should ensure that both gender are equally involved especially in Chemistry lessons to promote interaction in both gender and develop basic science process skills like critical thinking, measuring, observation and recording.

However, a study by Onyegegbu (2004) noted that boys participated more in interactions than girls hence contradicting the findings of the current study. Other studies have shown insignificant effect between interactions of both gender. For instance, the results from a study by Firooz (2016) which used independent t-test, revealed insignificant difference between male and female talk and the style of teaching, while a study by Noureen, Chaudhry \& Manzoor (2012) revealed no difference in the way Male and Female teachers interacted with learners using nonverbal behaviour neither was there significant difference in the way teachers of both genders praised and encouraged learners' activities to avoid tension in the classroom. Therefore, different studies have shown different outcomes and therefore, further research need to be done in different areas of the world. However, to analyze the effect of gender interaction on learner's academic achievement, two hypotheses were tested. 


\section{Testing of Hypothesis 1}

The first hypothesis stated that, "there is no statistically significant effect of gender interaction on academic achievement of learners in Chemistry". Testing of the hypothesis was done using the model $Y=B_{0}+B_{4} X_{4}+\varepsilon$. The results of the simple regression analysis on the effect of gender interaction on students' academic achievement were presented in Table 3.

Table 3: Simple Regression Analysis results on the effect of gender interaction on students' academic achievement

\begin{tabular}{|c|c|c|c|c|c|c|}
\hline \multicolumn{7}{|c|}{ Model summary } \\
\hline Model & $\mathrm{R}$ & $\mathrm{R}^{2}$ & Adj. $R^{2}$ & \multicolumn{3}{|c|}{ Std. Error } \\
\hline 1 & $0.114^{\mathrm{a}}$ & 0.013 & -0.022 & \multicolumn{3}{|c|}{14.40521} \\
\hline \multicolumn{7}{|l|}{ ANOVA } \\
\hline Model & Model & $\begin{array}{l}\text { Sum of } \\
\text { Squares }\end{array}$ & Df & $\begin{array}{l}\text { Mean } \\
\text { Square }\end{array}$ & $\mathrm{F}$ & Sig. \\
\hline \multirow[t]{3}{*}{1} & Regression & 76.048 & 1 & 76.048 & .366 & $0.550^{\mathrm{b}}$ \\
\hline & Residual & 5810.283 & 28 & 207.510 & & \\
\hline & Total & 5886.331 & 29 & & & \\
\hline \multicolumn{7}{|c|}{ Coefficients } \\
\hline \multirow[t]{2}{*}{ Model } & \multicolumn{3}{|c|}{$\begin{array}{l}\text { Unstandardized } \\
\text { Coefficients }\end{array}$} & $\begin{array}{l}\text { Standardized } \\
\text { Coefficients }\end{array}$ & $\mathrm{T}$ & Sig. \\
\hline & B & Std. & Error & Beta & & \\
\hline \multirow{2}{*}{$\begin{array}{l}\text { (Constant) } \\
\text { Gender }\end{array}$} & 49.829 & \multicolumn{2}{|c|}{3.487} & & 14.289 & 0.001 \\
\hline & 0.518 & \multicolumn{2}{|c|}{0.856} & 0.114 & 0.605 & 0.550 \\
\hline
\end{tabular}

a. Dependent Variable: Academic Performance (Student mean score)

b. Predictors: (Constant): Gender interaction

The simple regression analysis results in Table 3 shows that the effect of gender interaction on learners' academic achievement in Chemistry was not statistically significant. The two-tailed pvalue was found to be 0.550 . In relation to the decision rule: If $p \leq \alpha$, the null hypothesis is rejected. Therefore, since $0.550>0.05$, the null hypothesis was accepted and the study concluded that: "There is no statistically significant effect of gender interaction on learners' academic achievement in Chemistry".

Additionally, the outcome of this analysis shows that an increase in gender interaction by a single unit, increase the learners' academic achievement in Chemistry mean score by about 0.114 units. The statistic coefficient $\left(\mathrm{R}^{2}\right)$ provides the amount of variation that can be accounted for by the independent variable which is gender interaction. The value of $\mathrm{R}^{2}=0.013$, implying the model explain $1.3 \%$ variation in academic achievement which is the dependent variable in this study. Therefore $98.7 \%$ change in academic achievement resulted from other factors that were not part of the model. From this study gender interaction had only $1.3 \%$ effect on learners' academic achievement and it can therefore be concluded that gender interaction has no statistically significant effect on learners' academic achievement.

The findings of this study are consistent with a study by Dania (2014) on impacts of gender on learners' academic achievement in secondary school social studies revealed that academic achievement of learners' in secondary school Social Studies was based on techniques of classroom interaction used and are not affected by gender. Findings showed that gender interaction (male/female) insignificantly affected learner's academic achievement in Social Studies. The study recommended that gender should be disregarded during teaching and learning and instead both genders should be provided with equal chances and similar encouragement levels. 
However, the findings are inconsistent with findings of several studies. For example, Dee (2013) established that assigning a student teacher of same gender has a significant positive effect on achievement of students of both genders. This is probably due to the fact that, a girl view science as useful for her future when assignment is given by a female science teacher. This has the likelihood of such a girl to perform well in that subject. A study by Lee, Rhee and Rudolf (2007) analyzed the association between the gender of the teacher and that of the learners and the learners' achievement in Mathematics and reading. The findings of the study showed that learners instructed by females showed higher academic achievements than learners who received instructions from male teachers. Further results revealed that, the liking and academic performance of a subject was higher when learners received instructions from the same-gender teacher. Based on the results the study concluded that gender stereotyping in academic context is prevalent in teachers and students of both genders. Additionally, results of the current study differ from a study by Nnamani and Oyibe (2016) who investigated gender achievement of secondary school students academically in SST (Social studies) in Abakaliki urban of Ebonyi state that revealed that the mean achievement score of boys' learners in secondary school was lower than the average achievement scores of girls' learners. The findings of the study further revealed that students of both genders who were taught SST by a male teacher had a higher average score compared to when they are taught by a female teacher and that when female learners were taught SST by male teachers they performed better that the male students who were taught by a male teacher and vice versa. The study further established that variation in mean achievement in SST based on gender was significant among secondary school learners.

The findings are also in contrast with a study conducted by Okeke (2007) in Nigerian who found that female students suffer discrimination from teachers overtly and covertly, knowingly and unknowingly which automatically put the girls in a disadvantaged position for achievement in classroom interaction especially in science related subjects. The findings disagreed with Oleabhiele (2011) who held that the performance of male learners were better compared to that of the female learners in any classroom interaction activities that involve science education. These contrasts are probably arising after teachers become more sensitive to gender issues and change of attitude that girls have equal intellectual capacity to boys during learning. This is supported by findings of Ganai and Muhammad (2013) study on "Comparative Study on Adjustment and Academic Performance of College Students. "Based on gender, the researcher investigated the learners' academic achievement in different subjects. The study revealed that, the female students were found to be better in terms of enrolment and academic achievement in all the categories of subjects. This can be interpreted to mean that, the stereotype of classifying certain subjects as female or male ones is changing. This means that, the gender factor should not be an obstacle or hindrance in learning or teaching of any subject across the available curriculum. In fact teachers are currently motivating girls by telling them "what a boy can do, a girl can do even better." However, due to the many contradicting studies, more research need to be done on gender and academic achievement.

\section{Testing hypothesis 2}

The second hypothesis stated: There is no statistically significant relationship between gender interactions and academic achievement of learners in Chemistry. To test the hypothesis, Pearson Product-Moment Correlation Coefficient was used and results presented in table 4 below. 
Table 4: Pearson Product-Moment Correlation Coefficient between gender interaction and academic achievement.

\begin{tabular}{lll}
\hline \hline Variables & Academic achievement & Gender interaction \\
\hline Academic achievement & 1 & \\
Gender Interaction & $0.1137^{* *}$ & 1 \\
\hline
\end{tabular}

** Correlation is significant at $\mathrm{p}<0.05$ level (2-tailed)

The findings indicate a weak positive linear $(r=0.1137)$ correlation coefficient for the relationship between academic achievement and gender interaction. A value of $r$ close to 1.0 can be said to be a very strong relationship between any two values while a value of $r$ close to 0.0 can be said to be a very weak relationship between any two values (Kothari, 2012). Therefore, value $r=0.1137$ can be interpreted to mean there is no statistically significant relationship between gender interaction and learners' academic achievement. The findings are consistent with the findings from Simple Regression Analysis on the effect of oral interaction on students' academic performance in table 3 which revealed that "the effect of gender interaction on learners' academic achievement in Chemistry was not statistically and significantly related. Therefore, from the inferential statistics, the gender of a learner or a teacher has no influence on learners' academic achievement.

Several studies are in conformity with the current study. For instance a study by Oluwatosin and Ogbeba (2017) on influence of gender on achievement of senior secondary school learners in stoichiometry in Chemistry with the use of hands-on activities established that there was insignificant variation in average achievement score for learners of both genders taught stoichiometry with the use of hands-on activities. The results of a study by Dania (2014) on influence of Gender on learners' Academic Achievement in Secondary School SST provide empirical proof that the achievement of learners in SST is based on the teaching method used and not the gender of the student. Based on these studies, it can be concluded that the gender of the student has no influence or effect on effectiveness of the method used in teaching.

However, the results of this study are contradicted by several studies; for instance, a study by Fatokun and Odagboyi (2010) reported gender as a major factor in learners' academic achievement in Chemistry as a result of interaction. Torberg and Linn (2011) explored the educational evaluation schemes and gender gaps in student achievement in Norway and the study revealed that, in Norwegian, girls receive highest scores when assessed by a male teacher, and in Mathematics girls receive highest grades from low-experienced teachers. One interpretation of the results was that teachers favour girls, either deliberately or not. Therefore further research on gender is necessary especially considering the fact that majority of Kenyan public secondary schools are of mixed gender.

\section{CONCLUSION}

The conclusion arising from this study are: The stereotype of classifying certain subjects as female or male ones is changing while girls were found to be more interactive than boys. Learners preferred to be taught by teachers of own gender. Further, the study established that, there is no statistically significant effect or relationship between gender interaction and learners' academic achievement, hence, academic achievement of learners is a function of orientation and not gender. Finally, although many studies are consistent with the current study, several other studies shows inconsistent results, hence further research is necessary. 


\section{References}

Adigun, J., Onihunwa, J., Irunokhai, E., Sada, Y., \& Adesina, O. (2015). Effect of Gender on Students' Academic Performance in Computer Studies in Secondary Schools in New Bussa, Borgu Local Government of Niger State. Journal of Education and Practice, Vol.6, No.33, 2015, p 1-7.

Ajai, J.T.,\& Imoko,. I.I. (2015). Gender differences in mathematics achievement and retention scores: A case of problem-based learning method. International Journal of Research in Education and Science (IJRES), 1(1), 45- 50.

Akabogu, J. U., \& Ajiwoju, J. A. (2015). Effect of gender and school location on secondary school students' achievement English vocabulary in junior secondary schools in Akoka south education zone Ondo State. International Journal of Research in Humanities, Arts and Literature (IMPACT: IJRHAL). Vol. 3, Issue 6, P17-24.

Almut, E. T. (2017). Gender Differences in Students' Physical Science Motivation: Are Teachers' Implicit Cognitions Another Piece of the Puzzle?. American Educational Research Journal, Vol. 54, No. 1, p. 35-58.

Ammermueller, A., \&Dolton, P. (2006). Pupil-Teacher Gender Interaction Effects On Scholastic Outcomes in England and the USA. Centre for European research.

Berk, L.E. (2006). Child Development (7th edn). Boston, MA: Allyn \& Bacon.

Burusic, J., Babarovic, T., \& Seric, M. (2011).Differences in elementary school achievement between girls and boys: Does the teacher gender play a role? European Journal of Psychology and Education, vol 10 issue 2, p 83-101.

Christine, H. (2015). Gender and Classroom Interaction: A research review. The Scottish Council for Research in Education p 49.

Chua, K. H., \& Mageswary. (2015). The Interaction Effects of Gender and Grade Level on Secondary School Students' Attitude towards Learning Chemistry.Eurasia Journal of Mathematics, Science \& Technology Education, 11(4), 889-898.

Dania. P.O. (2014,).Effect of Gender on Students' Academic Achievement in Secondary School Social Studies. Journal of Education and Practice, Vol.5, No.21, p 78-84.

Dee, T. (2013).Teachers and the gender gaps in student achievement. 500 College Avenue, Department of Economics, Swarthmore College, Swarthmore.

Durán, N.C. (2015). Exploring gender differences in the EFL classroom. Colombian Applied Linguistic Journal no.8 Bogotá, Print version ISSN 0123-4641.

Fatokun, K. V. F., \& Odagboyi, I. A. (2010). Gender disparity and parental Influence on secondary school student's achievement in Nasarawa State. Journal of Research in National Development,8 (2a): p 8-12

Fatokun, K. V. F., \& Omenesa, K. A. (2015). Effect of prior knowledge and Classroom interactions on students' achievement in chemistry. African Educational Research Journal Vol. 3(3), pp. 184-189

Filgona1i, \&, Sababa, L.K. (2017). Effect of gender on senior secondary school students' academic achievement in geography in Ganye educational zone, Nigeria. European Journal of Education Studies, Volume 3, Issue 4, p 394410.

Firooz. (2016). The effect of teacher talk style on student achievement. International Journal of Educational and Psychological Researches Vol 8, p 45-59.

Gallagher, A.M., \& Kaufman, J. C. (2005). Gender differences in mathematics: What we know and what we need to know. American Psychological Association, p 122-149.

Ganai, M. Y., \& Muhammad, A. M. 2013. "Comparative Study on Adjustment and Academic Performance of College Students." Journal of Educational Research and Essays 1(1): p 5-8.

Greene, J. C., Benjamin, L., \& Goodyear, L. (2001).The merits of Mixing Methods in Evaluation: Evaluation, 7(1), 2544.

Hoque, K.E., Razak, A.Z.A., Mosa. F. Z. \& Reazul, I. (2013). Impact of Teacher- Gender on Primary Students' Achievement: A Study at Malaysian Standpoint. Journal of Sociological Research, Vol. 4, No.1, p 124-144

Hyacinth, E. (2000). Gender differences in education in Jamaica. Education for all in the Caribbean: assessment 2000 monograph series.

Kothari, C.R. (2012). Research Methodology. Methods and Techniques, Second Revised Edition. New age international (P) limited, publishers. New Delhi

Lauren, L.(2012).The importance of teacher-student relationships, as explored through the lens of the NSW Quality Teaching Model. Journal of Student Engagement: Education Matters Volume 2 | Issue 1, p 121-146. 
Lee, J., Rhee, D., \& Rudolf, R. (2007). Teacher Gender, Student Gender, and Primary School Achievement: Evidence from Ten Francophone African Countries. Graduate School of International Studies, Korea University, Division of International Studies, Korea University.

Lindsey, W. M. (2013).Examining gender and cultural influences on classroom Participation and interaction of students in an ESL and general Education classroom. Department of Language Learning and Leadership State University of New York at Fredonia Fredonia, New York

Myhill, D., \& Jones, S. (2006). 'She doesn't shout at no girls': pupils' perceptions of gender equity in the classroom. Cambridge Journal of Education, 36 (1), p 99-113

Nana, B. (2012). The Role of Gender-Biased Perceptions in Teacher-Student Interaction. Psychology of Language and Communication, Vol. 16, No. 1. Ilia state university, Tbilisi, p 154-172.

Natasha, M. (2016).The Role of Teacher Gender on Students' Academic Performance. https://lup.lub.lu.se/student-papers/search/publication/8880641-accessed on 19/11/2018.

Nematullah, S., Mohammad, A., \& Saeed, K. (2008). Classroom Interaction Mediated By Gender And Technology: The Language Laboratory Course. Novitas-ROYAL, 2008, Vol.: 2 (2), p 176-184.

Nnamani, S. C., \& Oyibe, O. A. (2016). Gender and Academic Achievement of Secondary School Students in Social Studies in Abakaliki Urban Of Ebonyi State. British Journal of Education, Vol 4, no 8, p 84-95

Noureen, A., Chaudhry, \& Manzoor, A. (2012). Teachers' Nonverbal Behavior and Its Impact on Student Achievement. Canadian Center of Science and Education, International Education Studies; Vol. 5, No. 4, p 56-64.

Milun, T., Mardesic, J., \& Kovac, G. (2011). Do gender and age impact on Student success?. University of Split, Zagreb, Croatia.

O'Connor, Dearing, E, Collins, B. A (2011). Teacher-Child Relationship and Behavior Problem Trajectories in Elementary School. American Educational Research Journal, P 67-84.

Oluwatosin, V. A., \& Ogbeba. (2017). Effect of Gender on Senior Secondary Chemistry Students' Achievement in Stoichiometry Using Hands-on Activities. American Journal of Educational Research, 2017, Vol. 5, No. 8, p 839842.

Onyegegbu, N. (2004). Interaction and gender in senior secondary school science Classroom. Journal of the Nigerian Academy of Education, 2(1): p 33-41.

Makila, A. (2015).Constructing gender in the EFL classroom: How Swedish uppersecondary school students perform in relation to gender in oral communication. Department of languages and literature, University of Gothenburg.

Marcus, S., \& Joakim, S. (2016). Gender differences in boys' and girls' Perception of teaching and learning mathematics Open Review of Educational Research. Open Review of Educational Research, 2016, Vol. 3, No. 1, 1834.

Mugenda, O. M., \& Mugenda, A. G. (2003). Research methods: qualitative and quantitative approaches. Nairobi, Acts press.

Noureen, A., Chaudhry, \& Manzoor, A. (2012). Teachers' Nonverbal Behavior and Its Impact on Student Achievement. Canadian Center of Science and Education, International Education Studies; Vol. 5, No. 4, p 56-64.

Okeke, E. A. C. (2007). Sex difference in the understanding of some important Biology concepts. Nigeria Journal of Education, 2(1), 125-132.

Oleabhiele, E. O. (2011). Effects of individualized and cooperative learning methods on senior secondary school students' achievement in Economics. An Unpublished Ph. D Thesis, Ebonyi State University, Abakaliki.

Palt., A (2018). To develop, continent needs more women to take up science. The L'oreal Foundation. Daily nation, Nairobi. 22nd, Dec 2018, p20

Perkins, R., Kleiner, B., Roey, S., \& Brown, J. (2004). The High School Transcript Study: A Decade of Change in Curricula and Achievement, 1990-2000. NCES 2004-455. National Center for Education Statistics.

Sheeba, F., \& Imran, K. (2015) Impact of Stress, Self-Esteem and gender factor on students' Academic Achievement. International journal on new trends in education and their implications, Vol: 6, issue: Article: 12, p 67-95.

Toni, M., Julija, M., \& Gordana, K. (2018). Do gender and age impact student success? College for Applied Computer Engineering "Algebra”, Zagreb, Croatia. 
Torberg, F., \& Linn, R. N.(2011). Educational Evaluation Schemes and Gender Gaps in Student Achievement. Working paper series. No. 4/2011. Norwegian university of science and technology.

Wenhua, H. D. (2012). Gendered EFL Classroom Interaction-A Case Study in a Senior Middle School in China. University of Technology, Dalian, China.

UNESCO. (2005). EFA global monitoring report 2005: The quality imperative. Paris: UNESCO.

UNESCO. (2000). Increasing the number of women teachers in rural schools: A synthesis of country case studies: South Asia. Bangkok: UNESCO Principal Regional Office for Asia and the Pacific. 